\title{
¿Existe un sistema andaluz de información y documentación?
}

\author{
Jesús Gómez Fernández-Cabrera \\ Jefe del Servicio de Documentación, \\ Archivo y Publicaciones. \\ Consejería de Gobernación. \\ Junta de Andalucia
}

\section{INTRODUCCIÓN}

Buscando dar respuesta a la pregunta planteada en el título del artículo, nos ocupamos en primer lugar de situar el problema en el marco de la sociedad de la información, abordando después el papel que la información tiene para las organizaciones y para la Administración, y la necesidad de establecer sistemas para su gestión (Apdo.2). A continuación se estudia la infraestructura organizativa: centros, redes y sistemas, a través de los cuales se lleva a cabo el tratamiento y difusión de la información y se explican sucintamente los elementos constitutivos de un Sistema de Información y Documentación (Apdo.3).

Una vez explicitados estos planteamientos teóricos, que nos facilitan los elementos para el análisis y la crítica, se presenta una visión panorámica de la situación de la Documentación en el ámbito de la Administración de la Comunidad Autónoma de Andalucía (Apdo.4) y por último se formulan algunas sugerencias sobre cual debería ser la política de información y documentación en Andalucía (Apdo.5).

\section{La sociedad de la información}

El papel determinante que en la actualidad juegan la información y las tecnologías de la información (TI) hace que nuestra sociedad se encamine a un nuevo modelo económico y social, al que hacen alusión las denominaciones de sociedad de la información, sociedad digital, sociedad del conocimiento, etc, con las que se quiere resaltar la incidencia de la información en los nuevos modos de vida y de trabajo. Primero los servicios, y ahora la información, han ido desplazando a las actividades centradas en la transformación de materias primas (sociedad industrial), añadiéndose a la tradicional división de los sectores económicos (agricultura, industria y servicios) un nuevo sector, denominado cuaternario, que con su acelerado ritmo de expansión, se está imponiendo como hegemónico. Si los elementos de la sociedad industrial eran el capital y el trabajo y su tecnología era mecánica, en la sociedad postindustrial estos elementos son la información y el conocimiento, y predomina la tecnología intelectual!.
Los avances tecnológicos, especialmente los producidos en el campo de los semiconductores, y la confluencia de las técnicas de transmisión de datos con las técnicas de tratamiento de información, están haciendo posible este nuevo modelo social y productivo. La conjunción de la informática (tecnología automatizada del proceso de datos) con las telecomunicaciones conforman lo que conocemos como Tl. Entre las nuevas $\mathrm{TI}$ destacan las referidas al tratamiento, almacenamiento y transmisión de datos e información y los sistemas de entrada y salida de datos. Estos avances tecnológicos han posibilitado una serie de aplicaciones tecnológicas tales como el correo electrónico, automatización de la gestión de oficinas, transferencia electrónica de fondos, teleconferencia, televisión y videoconferencia por cable, multimedia, etc.

Esta revolución tecnológica² comporta una capacidad, que parece infinita, para contener y manipular información. Como indica Richieri³, la sociedad de la información trata de la producción, elaboración, circulación y consumo de gran cantidad de datos y de conocimientos de todo tipo (económicos, científicos, políticos, públicos, privados, etc.), relativos a individuos, colectivos, naciones, y referidos a todos los campos de la actividad humana.

\section{Información y tecnologías de la información}

En este contexto se enmarca el esfuerzo y las grandes inversiones en $\mathrm{Tl}$ que las organizaciones, en particular las empresas, han llevado a cabo en las dos últimas décadas, en busca de un aumento de la competitividad y la productividad. También la Administración Andaluza, en sintonía con este desarrollo tecnológico, está llevando a cabo un evidente y significativo esfuerzo encaminado a la implantación de TI en el seno de su aparato administrativo ${ }^{4}$.

Los avances de las tecnologías y el uso inteligente de las TI han hecho posible, aunque sin llegar a los niveles esperados, la aceleración del ritmo de crecimiento de la productividad y el aumento de la eficacia en las organizaciones. Es importante reseñar que el uso inteligente de las TI comporta tener en cuenta las dos caras que, según S. Zuboff5', tienen las TI: Por un lado las TI tienen por objeto la "automatización" de las acciones humanas (incidiendo en su reproducción, aumento o mejora), y por otro llevan a la "informacionalización" de las tareas, ya que los programas también registran datos sobre las actividades automatizadas, generando así nuevas corrientes de información, es decir al funcionar producen información. 
Nadie pone en duda hoy día las ventajas que reporta la automatización de tareas rudimentarias o repetitivas, pero no existe la misma anuencia a la hora de considerar que la clave para el mayor aprovechamiento de las potencialidades de las TI está en explotar al máximo los recursos de información que las propia organización obtiene, genera y maneja ${ }^{6}$. Como señala Zuboff, a fin de explotar todo el potencial de la tecnología de manejo de datos, las organizaciones necesitarán en cada uno de sus niveles gente que sea capaz de analizar y de responder a los datos más importantes para sus respectivas responsabilidades funcionales. Esto implica una nueva visión de la organización y una estrategia de despliegue de tecnología que dé preminencia a las capacidades "informacionalizadoras" de las tecnologías de la información (página 228)7. Las organizaciones lejos de limitarse a implementar procesos de automatización, deben usar las TI para una mejor gestión y utilización de la información que fluye en su seno.

\section{LA INFORMACIÓN EN LAS ORGANIZACIONES}

El término información, con su gran carga polisémica, se aplica en campos muy diversos: como artículo de consumo, como estímulo en la Psicología, como representación del conocimiento interno, como mensaje en las Ciencias de la Comunicación, como noticia en el Periodismo, ... como datos y documentos en el ámbito de la Biblioteconomía y Documentación ${ }^{8}$.

Por información entendemos aquí los datos o conocimientos considerados novedosos o relevantes en un momento dado y por un receptor específico, a fin de paliar su ignorancia o reducir su incertidumbre sobre una materia, originando un nuevo estado de conocimiento cuya estructura no ha de verse necesariamente modificada por aquella?. Más adelante se completará y comentará esta definición.

\section{Gestión de recursos de información}

Ya es un tópico decir que la información es poder, expresión que podemos explicar en el sentido de que el éxito de una organización en la consecución de sus objetivos no depende solamente de la gestión de sus recursos (tangibles) materiales, humanos y económicos, sino de la correcta gestión de su recursos (intangibles) de información. Gestión que depende de que exista un adecuado flujo de información entre la organización y su entorno y entre las distintas unidades que componen la organización.

Cuando nos referimos a la información como recurso estamos aludiendo a que la información es un elemento imprescindible para el funcionamiento de las organizaciones y que la función que desempeñan quienes se dedican al manejo y tratamiento de la información debe ser valorada justamente. Y por otro lado estamos diciendo que como tal recurso, a la información pueden y deben de aplicarsele las técnicas clásicas de gestión de recursos: planificación, organización, dirección y control.
Hay que decir, no obstante que la información es un recurso atíico, que se diferencia de los bienes materiales, por lo que los medios aplicados para administrar las cosas, tales como el control, la propiedad, el monopolio, etc., se aplican con dificultad a la l, lo cual ha provocado que, a partir de los años 70, sobre todo en el mundo anglosajón, se hayan dedicado esfuerzos para el desarrollo de metodologías concretas para la gestión de recursos de información (Information Resources Management).

La Gestión de Recursos de Información (GRI), es definida de forma oficial en los EUA, en el año 1985, como la [práctica] de la planificación, presupuesto, organización, dirección, formación y control relacionados con la información de la Administración [government information]. el término engloba tanto la información en sí como los recursos relacionados, tales como el personal, equipo, fondos, y tecnología (Circular A- I 30 de la Officce of Management and Budget de la Oficina Ejecutiva del Presidente de los Estados Unidos'o.

La GRI es una disciplina en desarrollo, en la que participan profesionales pertenecientes al mundo de la Informática, de la Administración de empresas y de las Ciencias de la Información y Documentación, que dispone de un cierto corpus teórico y de un conjunto de técnicas y metodologías concretas para la gestión de la información.

En palabras de A.Cornella, el objetivo de la GRI será la explotación de los datos, información (formal e informal) y conocimientos en las organizaciones, tanto a la entrada como a la salida y en el interior de las mismas, y para ello deberá coordinar todos aquellos departamentos cuyo objetivo fundamental sea el manejo de información (por ejemplo, departamentos de informática, marketing, investigación y desarrollo, planificación estratégica, biblioteca, etc).

La GRI debe considerar tres funciones o componentes distintos: a) la información y conocimientos de la organización que se deben gestionar, b) las TI (informática y telecomunicaciones); c) los sistemas de información, entendidos como medios para transformar la tecnología en algo de valor para el usuario y para la organización.

\section{Sistemas de información en las organizaciones}

Ya hemos hecho alusión a los distintos tipos de información que suelen existir en las organizaciones: a) Informaciones de gestión: Conjunto de datos que requiere un organismo para su trabajo cotidiano, suelen estar imbricadas con los procesos de explotación y gestión de recursos; b) Información factual o estadística, que proporciona información del entorno y facilita la toma de decisiones; c) Información documental: cualquier información, dato o conocimiento registrado sobre un soporte (documento). En consonancia con esta tipología informativa, Van Slype ${ }^{12}$ distingue muy acertadamente entre Sistemas de Información responsables de la información de gestión y factual, y Sistemas de Información Documental que gestionan la información documental. 
Un sistema, según la Real Academia, es un conjunto de cosas que ordenadamente relacionadas entre sí contribuyen a un determinado objeto. Bertalanffy define los sistemas como conjuntos de elementos en interacción ${ }^{3}$. $T$. Baiget desde un punto de vista técnico define el sistema como la entidad constituída por partes que interaccionan entre sí de una forma dinámica, coordinadas para conseguir objetivos comunes. Por "dinámica" se quiere indicar "de una forma activa", no necesariamente lineal o proporcional, y adaptada a cada situación momentanea ${ }^{4}$. Un sistema se caracteriza por su estructura interna, su entorno y por la clase de entradas y salidas que acepta.

\section{Sistemas de Información (SI)}

La denominación Sistemas de Información se emplea en diversos contextos: a) Psicología y Sociología: en relación con la comunicación y el impacto que tiene los $\mathrm{SI}$ en su entorno, las reacciones de las personas, de la sociedad, etc.; b) Gestión empresarial: relacionado con el manejo de datos relativos a ventas, compras, costes, etc; c) Informática y Comunicaciones: referido a la automatización de procedimientos, estructuración de datos (bases de datos y organización de ficheros), telecomunicaciones, etc. Son los informáticos los que han patrimonializado el término.

Desde una perspectiva organizacional (conjuntando los ámbitos empresarial e informático), un SI es una clase de sistema especializado, cuya actividad consiste en realizar determinadas transformaciones sobre unas entradas consistentes en datos o información y producir unas calidad consistentes en información con valor añadido o información que facilita la acción y la toma de decisiones. En otras palabras, un SI es un sistema que reune, almacena, procesa y proporciona información a una organización (o a la sociedad), de tal manera que la información sea accesible y útil a aquellos que deseen utilizarla (gestores, directivos, clientes, ciudadanos) $)^{15}$.

Los elementos que integran el SI son: a) la información (documental o no); b) los miembros de la organización y los agentes sociales que con ella se relacionan; c) los procesos y soportes de la información.

Los objetivos de un SI son: a) la resolución de problemas; b) facilitar la toma de decisiones; d) la acumulación de conocimientos. Este último objetivo no se considera como tal por muchos autores y es descartado en la definición de objetivos de ciertos sistemas. Por otro lado la definición marca una de las especificidades de los SID, como veremos a continuación.

\section{Sistemas de Informacion Documental (SID)}

Un SID es un sistema que acepta documentos y necesidades de información como entradas y produce personas informadas como salida. El propósito de un sistema de información documental es explotar la información y el conocimiento registrado en los documentos para ponerlos al servicio de los usuarios 16 .
Los SI convencionales están diseñados para automatizar actividades (las actividades de la propia organización) y para el tratamiento de informaciones factuales y de gestión, mientras que los SID se ocupan de la gestión de información documental

Detengámonos un momento y veamos qué se entiende por información documental. La información es una propiedad que poseen algunos objetos/procesos, que presenta una doble dimensión: en sentido absoluto la información es la capacidad de esos objetos/procesos de dar a conocer algún aspecto de la realidad, y en sentido relativo la información es el incremento de conocimiento que experimenta un sujeto después de recibir un mensaje.

Se habla de información documental cuando lo que se aporta son documentos cognitivos, o referencias de esos documentos, que contienen esos datos o conocimiento sobre la realidad. Un documento es una información registrada en un soporte material, creado con la intención de comunicar y que en su forma final puede ser leido por el hombre. Son documentos cognitivos aquellos que contienen obras de creación cultural, científica o técnica.

La explotación de la información contenida en este tipo de documentos, plantea una problemática particular originada por la incertidumbre que rodea la reutilización de documentos cognitivos, ya que en el momento del almacenamiento de los documentos cognitivos se desconoce cual de sus atributos será necesario recuperar más adelante, y también se desconocen las futuras necesidades de información que planteará el posible usuario. Es más, la información no tiene un valor absoluto, sino que el receptor la interpreta en función de su propia predisposición, dando lugar a un significado concreto.

Este hecho obliga a representar cada documento describiendo sus atributos formales (autor, títulos, etc) y semánticos (contenido, alcance, etc.). Y no existen fórmulas ni normalizaciones capaces de valorar cual es la representación más adecuada, y que garanticen la relevancia y pertinencia de los documentos en el momento de proceder a su recuperación, ya que ni el contenido de un documento, ni las necesidades de información del usuario son cuantificables.

De lo dicho se deduce que la Informática, que resulta imprescindible para automatizar los procesos dentro de un SID, no puede sin embargo aportar la estructura lógica del SID. Es la Documentación la que aporta los métodos y los procedimientos tecnológicos y científicos que deben implementarse en los SID.

La Documentación, como disciplina específica, se ocupa del estudio de la representación, almacenamiento, recuperación y difusión de los conocimientos registrados en este tipo de documentos. A la Documentación compete definir las propiedades, características, técnicas y procedimientos de los SID, y estudiar la problemática relacionada con el análisis, diseño y gestión de los SID. 
El estudio y tratamiento de la información documental es un campo amplio, que incluye al menos estos tres sectores: Archivística, Biblioteconomía y Documentación. La Archivística, se ocupa especialmente en la conservación y tratamiento de documentos administrativos. La Biblioteconomía está volcada al mundo de las bibliotecas y especialmente en la lectura pública. La Documentación tiene como objetivo la documentación científica y técnica. Biblioteconomía y Documentación estan ligadas por muchos vínculos, mientras que la Archivística está situada en un ámbito propio y diferenciado.

Lo dicho de las disciplinas puede aplicarse a los respectivos centros o unidades documentales: archivos, bibliotecas y centros de documentación. No obstante lejos de buscar elementos diferenciadores, aunque se constaten, deben buscarse instancias de confluencia, sobre todo en el momento de la implantación y desarrollo de un SID en una organización. Las diversas unidades documentales coinciden en el manejo de un mismo elemento: los documentos y coinciden en el empleo de técnicas muy similares para su procesamiento y manipulación. Y lo que es más, sirven a una misma organización, en la que la presencia de sistemas integrados de gestión de la información obligará cada vez más a la confluencia.

\section{SISTEMAS, REDES Y UNIDADES DOCUMENTALES}

Pretendemos ocuparnos ahora de las instancias organizativas que se encargan de concretar físicamente las tareas documentales de que venimos hablando, estableciendo el puente entre la teoría y la realidad cotidiana.

Intentaremos explicar la interrelación entre estos tres conceptos, a la vez que explicamos su significado: Unidades documentales, redes y sistemas.

\section{Unidades documentales}

De siempre las instituciones y organizaciones se han dotado de unidades o centros especializados en la conservación y organización de documentos y en la elaboración de la información. Ya hemos hecho referencia a la diversidad de estos centros. A la dificultad que entraña la diversidad ya apuntada, hay que añadir la confusión terminológica originada por la diversidad de referentes que en nuestra lengua suele tener un mismo término, que puede hacer referencia (por ejemplo la palabra archivo) tanto a la colección documental, a la institución documental que la conserva y trata, $y$ al edificio en que ambas se asientan.

Para posibilitar el entendimiento, sin ningún ánimo reduccionista, sino por el contrario buscando una denominación genérica en la que tengan cabida los distintos tipos de instituciones documentales diremos, con L.F. Ramos Simón, que unidad documental es aquella institución documental atendida por especialistas en información y documentación que tiene por objeto la recogida, análisis y tratamiento de la información generada por fuentes internas y/o externas a la organización de la que forma parte; para lo que emplea medios personales, recursos técnicos y económicos, al objeto de someter la información a un tratamiento técnico documental que crea utilidad (económica o social) para los usuarios a quienes pretenden satisfaceri7.

La caracterización y clasificación de las unidades documentales no ha sido uno de los objetos de estudio prioritario por parte de los estudiosos. No obstante, existe una clasificación de instituciones documentales comunmente aceptada: Archivos, Museos, Bibliotecas y Centros de Documentación, cuyas respectivas especificidades radican en la mayor o menor insistencia que cada una pone en las distintas operaciones del proceso informativo documental (conservación, difusión, análisis, etc) y en la naturaleza y características de los documentos que cada una de ellas trata. Así C. Guinchat y M. Menoul8 establecen una tipología distinguiendo tres ramas: a) Conservación y suministro de documentos primarios: archivos, bibliotecas, museos; b) Descripción del contenido de los documentos y su difusión, indicación de la información y sus fuentes: centros de documentación; c) Respuesta a las consultas concretas, utilizando la información disponible, incluida su evaluación y transformación: centros de información

Bibliotecas y archivos son instituciones consolidadas, con larga trayectoria, y con una tipología más o menos definida y aceptada. No ocurre así con los centros de documentación. Es prolija la diversidad de fórmulas organizativas, fines, titularidad, etc. de estos centros, y en consecuencia son variadísimas las denominaciones: servicio de información, centro de documentación, servicio de documentación, centro de información, servicio de difusión, etc. Diversidad que contrasta con las similitudes existentes en el ámbito de su gestión. Optamos por emplear el término centro de documentación, que en España se encuentra bastante consolidado como denominación genérica para referirse a la pluralidad de fórmulas existentes en el sector ${ }^{19}$.

Los centros de documentación tienen como finalidad proveer de productos oly servicios de información a sus organizaciones (caso de tratarse de un servicio integrado en una institucion), a determinados colectivos o a la sociedad en general. Hemos hablado de "productos" refiriendonos a los que ya existen elaborados en el mercado dispuestos para su adquisición (compra), como son las publicaciones, bases de datos, etc., que contienen la misma información para todos los usuarios. Y hemos hablado de "servicios" para referirnos a aquella información que el usuario demanda especificamente y que no se encuentra entre los productos del mercado. Estos servicios de información se diferencian en la calidad y/o cantidad de valor añadido por el documentalista a la información, para que se ajuste a las necesidades del usuario. Este valor puede consistir en la garantía de fiabilidad y exahustividad de las fuentes de información utilizadas o facilitadas al usuario, en la prontitud, agilidad y utilidad del servicio, en la incorporación de consejos y recomendaciones (en el caso de consultorias), etc. Los servicios de información pueden versar tanto sobre la información interna como la externa. 
Por último, señalar que los centros de documentación, en el seno de las organizaciones deben liderar, en el marco de la integración de sistemas de gestión de la información, el diseño e implantación de un SID que se ajuste a las necesidades de la organización.

\section{Redes de información}

Ante la dispersión de fuentes y unidades documentales surgen las redes, que no son otra cosa que unidades documentales interconectadas, que conservando su autonomía pretenden algún objetivo común.

La configuración de las redes está en función (a la vez que determinan) de los canales de comunicación y el flujo de los mensajes.

El principio que rige el funcionamiento de las redes es el de la coordinación, produciendose una distribución de responsabilidades entre los centros que la integran en cuanto a la adquisición y difusión de fuentes.

La tipología de las redes es variada. Las redes pueden establecerse con criterios territoriales (locales, provinciales, autonómicas/regionales, nacionales), con criterios de especialización temática, en base a las funciones documentales (adquisición, catalogación, discusión),o en función del tipo de usuarios, etc. Y siempre pueden compaginarse varios de estos criterios.

En España existen proyectos de trabajo en red tales como REBIUN (Red de bibliotecas universitarias), DOCUMAT (Bibliotecas especializadas en el área de Matemáticas), Red de bibliotecas del CSIC.

\section{Sistemas de información y documentación}

La unidad documental es la organización documental básica, la red aparece como una relación de centros sin jerarquía y el sistema se presenta como un conjunto de redes coordinadas 20

Podemos hablar del Sistema andaluz de bibliotecas (Red de bibliotecas públicas, Red de bibliotecas universitarias, etc,), del Sistema Andaluz de Archivos, y del Sistema Andaluz de Centros de Documentación (Red de centros de la Comunidad Europea, Red de centros al servicio de la Administración Autonómica, etc.).

El sistema actúa bajo el principio de centralización, predominando un sentido jerárquico de subordinación, asumiendo las distintas redes las normas emanadas del sistema21.

Los sistemas se articulan en base a tres instancias: a) Centros (con sus fondos y medios materiales y personales); b) Organismos (que ejercen las funciones de dirección y consulta); c) Políticas de información.

De la conjunción de sistemas, redes y centros, organismos y políticas de información surgen los que se suelen denominar Sistemas de información y documentación 22 .

\section{Políticas de información ${ }^{23}$}

Las políticas de información surgen ante la necesidad de información que experimentan los individuos, las empresas, la Administración. El sumatorio de esas necesidades plantea una exigencia colectiva (autonómica, nacional e incluso internacional) a la que debe responder la Administración por su capacidad para concertar esfuerzos y por ser ella una de las instancias en las que se da mayor volumen de demanda, producción y tratamiento de la información.

Debe existir una estructura institucional en la que los órganos de dirección formulen las políticas y los programas, los órganos de coordinación posibiliten y supervisen la puesta en marcha de esas políticas y programas y las unidades y redes documentales que hagan posible la ejecución de lo planificado y, en definitiva, provean a la comunidad de los productos y servicios informativos que esta demande o necesite.

\section{Políticas autonómicas de información}

Las Comunidades Autónomas han asumido importantes competencias transferidas del Estado referentes al sector de la documentación, cosa lógica, puesto que el autogobierno exige la capacidad de disponer de la información que facilite las decisiones del gobierno y administracion autonómica, y por otro lado porque en una dinámica de acercamiento de la gestión a los ciudadanos, la gestión de los recursos de información debe jugar un papel determinante en lo relativo a captación y reunión de fuentes, prestación de servicios al público, a las empresas y a la propia administración.

Las competencias transferidas tienen que ver con instituciones documentales como son las bibliotecas y los archivos, con el control bibliografico a través del depósito legal, las estadísticas autonómicas, cartografía, etc. Existen otras competencias relativas a organismos que no siendo instituciones documentales (organismos de investigación, universidades, Cámaras de Comercio, Industria y Navegación, etc.), resultan imprescindibles para llevar a cabo una política de información, y que tienen capacidad para prestar servicios de información (formación de profesionales, producción de bases de datos, mantenimiento de centros y servicios de información).

Las políticas autonómicas ${ }^{24}$ en nuestro sector no deben buscar ni la autosuficiencia, ni la repetición del modelo nacional. La política nacional debe ser el marco que propicie y aglutine las políticas autonómicas y facilite la coordinación con otros sistemas nacionales e internacionales.

La política autonómica, por otro lado tendrá como prioritario la coordinación de los centros y sistemas de su territorio. Para ello se deberá proceder un determinado desarrollo legislativo autonómico 


\section{EL CASO DE ANDALUCÍA}

Para hacer un retrato de la situación andaluza vamos ha considerar en primer lugar cuál es la realidad de los distintos subsistemas: Sistema Andaluz de Bibliotecas, Sistema Andaluz de Archivos y Sistema Andaluz de Centros de Documentación (con especial detenimiento en este), y en segundo lugar indagaremos acerca de las políticas andaluzas de información y documentación ${ }^{25}$.

\section{Sistema Bibliotecario de Andalucía}

La política autonómica en materia de información y documentación ha girado fundamentalmente en torno a las bibliotecas públicas. Alrededor de este eje se han movido las acciones ejecutivas y legislativas, comportamiento por otro lado similar al resto de las administraciones autonómicas y central. Esto ha posibilitado la consolidación de un subsistema bastante estructurado.

El Sistema Bibliotecario de Andalucía, está constituido26 por: a) Órganos:Coordinador General de Instituciones, Investigación y Difusión del Patrimonio Histórico, Dirección de la Biblioteca de Andalucía, Consejo Andaluz de Bibliotecas, y Comisión de Coordinación del Sistema Bibliotecario de Andalucía ${ }^{27}$. b) Centros bibliotecarios: Biblioteca de Andalucía, como cabecera del sistema, las Bibliotecas Públicas Municipales y demás bibliotecas de uso público de competencia autonómica radicadas en Andalucía.

\section{Sistema Andaluz de Archivos 28}

Los centros que forman parte del Sistema Andaluz de Archivos son los Archivos Centrales ${ }^{29}$ de las Consejerías, Organismos Autónomos y Empresas de la Junta de Andalucía, los Archivos de las Corporaciones Locales, los restantes Archivos públicos y privados que se integren en el Sistema.

Los órganos responsables del Sistema son: Coordinador General de Instituciones, Investigación y Difusión del Patrimonio Histórico, Dirección del Archivo General de Andalucía, Comisión Andaluza de Archivos y Patrimonio Documental y Bibliográfico, Comisión de Coordinación del Sistema Andaluz de Archivos y los órganos directivos de los Archivos Históricos Provinciales y del Archivo de la Real Chancillería de Granada.

El Plan Andaluz de Archivos, como desarrollo del Plan General de Bienes Culturales ${ }^{30}$, parte de las necesidades de superar las carencias y deficiencias en los archivos andaluces, y acomete la planificación de las medidas necesarias para conseguir un desarrollo correcto de las instalaciones, la Defensa del Patrimonio Documental, y el incremento de la función cultural y social de los archivos, con especial incidencia en las medidas de tutela del Patrimonio Documental Andaluz3!.

Es de interés indicar, por la relación del tema con lo hablado más arriba sobre la gestión integrada de la documentación en las organizaciones y más en concreto en los organismos de la Administración autonómica andaluza, que la política y planificación archivísticas, en lo que atañe a estos centros, deben alejarse de enfoques y planteamientos culturalistas, teniendo en cuenta las particularidades que presentan los archivos de gestión, para evitar que los archivos administrativos se ubiquen como islas documentales en su propio centro y como un archipiélago en el seno de la Junta de Andalucía.

\section{Sistema Andaluz de Centros de Documentación}

En nuestra Comunidad Autónoma se ha producido un importante proceso de institucionalización de centros de documentación, por la vía de los hechos, sin que exista ninguna norma reguladora común a todos ellos. No puede hablarse de sistema, por la ausencia de órganos de dirección colectiva y falta de planificación general, pero de hecho existe una red o sistema más o menos informal, que con diferentes niveles de desarrollo presta el servicio que la Administración le encomienda o demanda. Por otro lado se han implementado importantes sistemas de gestión y difusión de información.

\section{Centros de documentación de la Administración andaluza ${ }^{32}$}

En el sector público la necesidad de gestionar información se plantea desde dos ámbitos: Por un lado la obtención, almacenamiento, recuperación e intercambio de información es una exigencia imperiosa para el desarrollo de la actividad propia de la Administración; por otro, la Administración debe facilitar información para aumentar la calidad de vida del ciudadano y debe proveer a este ciudadano de cuanta información necesite para permitirle las relaciones con la propia Administración en todos los actos administrativos. La Administración necesita dotarse de una infraestructura que satisfaga estas necesidades, y así lo ha hecho la Administración andaluza, tal como vamos a ver.

Nos vamos a ocupar en primer lugar de los centros que están integrados y dan servicio a los organismos administrativos (consejerías, organismos autónomos, empresas públicas) de la la Junta de Andalucía, y a continuación lo haremos de las instituciones documentales autónomas existentes en nuestra Comunidad.

En la Junta de Andalucía existen dos tipos de organismos, como en el resto de la Administración Pública: departamentos sectoriales con funciones de gestión y organismos de tipo horizontal con funciones de estudio y apoyo técnico en áreas temáticas concretas. En cada una de estas instancias se genera y utiliza información y documentación, en parte común a todos los organismos (normativa jurídica, jurisprudencia, información de la Junta de Andalucía, etc.), y en parte diferenciada en función de las actividades que le son propias a cada uno de ellos 33 . 
La Ley de Gobierno y Administración de la Comunidad Autónoma ${ }^{34}$, a semejanza de la Administración Central35 asigna a las Secretarías Generales Técnicas funciones tales como realizar estudios y reunir documentación sobre las materias propias del Departamento, preparar compilaciones de las disposiciones vigentes, cuidar de las publicaciones técnicas, dirigir y facilitar la formación de estadísticas, y otras más genéricas como mejorar la organización y métodos de trabajo y coordinación de los servicios. En consecuencia, cada organismo, que es responsable individualmente de la gestión de la información y documentación que necesita y/o produce, se ha ido dotando a lo largo del tiempo de los recursos organizativos, humanos y tecnológicos que dentro de sus posibilidades cada uno ha creído oportuno.

El conocimiento lo más exacto posible de la situación en cada uno de los organismos, podría facilitar el diseño de políticas de información y documentación en el seno de la Junta de Andalucía y el establecimiento de cauces de colaboración sobre bases reales. No disponiendo de este conocimiento, y con ánimo constructivo, a continuación se comentan algunas circunstancias de nuestro "sistema" de centros de documentación que urge mejorar.

Uno de los principales problemas es el de la dispersión y descoordinación entre los centros de documentación de los distintos organismos. Son escasas las colaboraciones formales y estables.

Es muy desigual, por regla general bajo, el nivel de integración de estros centros en la actividad y estructura de la propia organización a la que pertenecen, siendo escasos sus recursos personales y de infraestructura.

Son escasas las conexiones con otros sistemas (universidades, bibliotecas públicas, archivos, ...) y las actividades de colaboración.

Es frecuente la presencia de situaciones equívocas en cuanto a la realización de tareas documentales en el seno de consejerías y organismos, dándose, en este sentido multiples situaciones: a) Realización de tareas documentales por personas cuya preparación no es la del profesional de la documentación, y que ocupan un puesto de trabajo cuyo perfil no pertenece al área de Documentación. Ocurre incluso que son varios los puestos de trabajo que se dedican a hacer trabajos documentales, de forma aislada y sin formación, en el seno de un mismo organismo. b) En un mismo organismo operan varias unidades definidas en la Relación de Puestos de Trabajo como pertenecientes al área de Documentación, que duplican recursos y reiteran trabajos. Cada uno cubre las necesidades de parcelas aislada del organismo a que pertenecen, sin ningún tipo de coordinación. c) Se dan organismos en los que existe una unidad documental que opera en el ámbito global de la institución, en lo relativo a la gestión de documentación bibliográfica. En estos casos la unidad documental puede convivir con alguna de las situaciones descritas arriba, y módulos, entre los que no exis- ten puntos de conexión: gestión de documentación administrativa (archivos), gestión de documentación bibliográfica (biblioteca/centro de documentación) y documentación periodística (gabinetes de prensa).

Se ha de conseguir, evitando la dispersión y descoordinación, la integración necesaria para llegar a constituir auténticos Sistemas de Gestión de Recursos de Información en cada uno de los correspondientes organismos.

Respecto al otro tipo de instituciones documentales, decir que desde instancias distintas la Administración ha ido creado centros y sistemas con una definición documental clara y definida, cuando ha surgido la necesidad de conservar, tratar y/o servir documentación e información especializada. Así han surgido organismos como el Centro de Documentación Musical, Instituto de Estadística de Andalucía, Filmoteca de Andalucía, etc. Existen También centros que estando incardinados en un organismo superior, estan diseñados para dar servicio más allá del organismo al que pertenecen: Instituto Cartográfico, Centro de Documentación del Patrimonio Histórico, Biblioteca de la Escuela de Salud Pública, Departamento de Documentación del Instituto Andaluza del Deporte, Centro de Documentación Juvenil, Oficinas de Información Administrativa al Ciudadano, Centro Servidor de Videotex de la Junta de Andalucía, Centro de Información y Documentación de la Junta de Andalucía (CIDJA), que desde la Consejería de la Presidencia produce la Base de Datos del $\mathrm{BOJA}$, etc .

\section{Sistemas de información de la Junta de Andalucía.}

En otro orden, la Administración andaluza ha implementado diversos sistemas de información de ámbito autonómico, al abordar la automatización de la gestión de distintas áreas funcionales tales como: Gestión económica y seguimiento presupuestario (JUPITER), Tratamiento de Expedientes de la Junta de Andalucía (TEXIA), Sistema de Información de Recursos Humanos de la Junta de Andalucía (SIRhUS), Sistema de Información de Medio Ambiente, (SINAMBA) Sistema de Información del Patrimonio Histórico Andaluz (SIPHA), etc.

Estos sistemas además de implantar un alto grado de normalización en la gestión, son básicos en el procesamiento de información necesaria para la gestión y toma de decisiones en el ámbito de la Administración autonómica

\section{Organismos y competencias sobre Documentación en Andalucía}

Ya hemos dicho que no existen órganos que de forma unitaria y coordinada ejerzan las funciones de dirección y asesoramiento en este sector. No obstante en la Administración Autonómica existen instancias que tienen asignadas competencias de planificación, dirección y coordinación en campos que tienen que ver con la gestión de información y 
documentación. Sin ánimo de exhaustividad, hagamos un recuento de estas instancias. La Consejería de Gobernación ${ }^{36}$ tiene competencias sobre los sistemas informáticos y las comunicaciones. La Consejería de Cultura $^{37}$ es responsable de archivos y bibliotecas . La Consejería de Educación ${ }^{38}$ tiene competencias sobre las universidades e investigación. En la Consejería de Trabajo e Industria39 residen competencias sobre programas de normalización, calidad e I+D. A la Consejería de la Presidencia le corresponde la organización de los medios de comunicación dependientes de la Administración Autonómica (D.G. de Comunicación Social) ${ }^{40}$, la canalización de la información relativa a la Unión Europea (D.G. de Asuntos Europeos) $)^{41}$, y la coordinación de los servicios de prensa de las distintas consejerías (Portavoz del Gobierno) ${ }^{42}$, Etc.

\section{POLÍTICA ANDALUZA DE INFORMACIÓN Y DOCUMENTACIÓN}

Desde estas diferentes instancias, la actuación de la Administración andaluza, como la del resto de las Administraciones, se ha caracterizado por su falta de globalidad. Las actuaciones de los poderes públicos en nuestro área se producen como consecuencia de iniciativas sectoriales independientes unas de otras, sin que se haya diseñado previamente un plan general, existiendo también la tendencia de producir normativas que regulan aspectos sectoriales sin que se articulen en un marco general, tal como ha venido ocurriendo en la Administración Central43.

Esta dispersión de instancias oficiales y la falta de coordinación de los esfuerzos realizados que podrían complementarse e interactuar, es un fallo detectado de antiguo en la Administración Central, en informes como el de la OCDE publicado en 197444.

Así pues pensamos que, para superar los niveles de realización actuales y avanzar a un estadio superior, es necesario que la Administración andaluza actúe en tres frentes: Marco jurídico, planificación y organismos e instituciones

\section{a. Marco jurídico}

En el aspecto normativo, es necesario el diseño de líneas de actuación y la promulgación de una ley que ordene el sector.

\section{b. Plan de Información y Documentación}

Deben elaborarse planes a largo y medio plazo para actividades documentales e informativas ligadas a otros elementos y sectores de desarrollo de la región, y por otro lado deben programarse y llevarse a cabo iniciativas para la promoción de proyectos de organización, técnicas, análisis, etc. del propio sistema.
Los objetivos principales de este plan deberían ser: a) Promoción de actividades y estudios en esta materia. b) Coordinación de los recursos e instituciones documentales de titularidad autonómica. c) La coordinación con los recursos e instituciones documentales de titularidad privada. d) Coordinación con el plan nacional de documentación 45

\section{c. Sistema Andaluz de Centros de Documentación}

Establecido que el sistema debe articularse en base centros y organismos, la actuación debe acometer dos frentes: En primer lugar dotar a la Comunidad Autónoma de una red de centros debidamente dimensionada y proporcionada, territorial y sectorialmente, completando las realizaciones presentes; y en segundo lugar se hace imprescindible la creación de un organismo de dirección que coordine y supervise la ejecución del Plan que previamente se haya elaborado.

En este sentido es necesaria y urgente la distribución racional de responsabilidades en los componentes del sistema sobre las materia siguientes: actividades de los centros en evitación de duplicidades, formación de profesionales ${ }^{46}$, relaciones nacionales e internacionales, servicios de asesoramiento, adquisición y recopilación de información (creación de fondos y acumulación de información relevante en todos los campos para la economía, la Administración, la ciencia, la tecnología, la educación, etc), procesamiento y evaluación de las fuentes, difusión de la información (publicaciones, bases de datos, Internet), redes de comunicación y telecomunicaciones, elaboración de metodologías, normas, directrices, estudios de prospectiva (necesidades y adecuación del sistema).

Hemos hablado de un organismo de dirección. A este respecto parecen existir dos soluciones ${ }^{47}$ : un organismo que centralice asumiendo las competencias decisorias y fiscalizadoras, o un organismo que articule la cooperación con capacidad ejecutiva, que asuma la coordinación con el resto de administraciones y que posibilite el establecimiento de un marco estable de cooperación con las entidades privadas que tengan incidencia en el sector.

La realidad tan diversa de centros y sectores y la desigualdad de niveles de implantación y desarrollo en los centros ya existentes, avala la segunda opción organizativa. A inclinarnos por esta solución contribuye también la evolución de los planteamientos informáticos, que al pasar de una filosofia centralizada a la descentralizada y actualmente a la informática repartida, favorece la definición de planteamientos globales para todos los organismos y dependencias de la Administración, contemplando la interrelación y conexión de las distintas actividades, y el aprovechamiento de las complementariedades existentes, sin que ello vaya en detrimento de que cada unidad pueda gestionar su información, al nivel necesario para ejercer sus funciones ${ }^{48}$. 
I. BELL, D :: El advenimiento de la sociedad postindustrial. Madrid: Alianza Editorial, 1976.

2. Las TI transforman el mundo que nos rodea, las organizaciones sociales e incluso a nosotros mismos. Y el continuo progreso de las TI suscita unas perspectivas de cambio social que resultan difusas. Conocemos el punto de partida, pero sabemos poco sobre el punto de destino. En este sentido es ilustrativa la visión pionera y anticipadora aportada por N. Negroponte, en su libro El mundo digital (Barcelona: Ediciones B, 1995), sobre presente y futuro de las T.

3. RICHIERI, G.: El universo telemático. Barcelona: Mitre, 1983

4. La Informática en la Junta de Andalucía. Sevilla: Consejería de Gobernación, 1993.

5. ZUBOFF, S.: In the age of the Smart Machine, The future of work and power. New York: Basic Books Inc, Publishers, 1988.

6. Según algunos autores, si el ritmo de aceleración de productividad en ciertos sectores o empresas no ha sido esperado, viéndose defraudadas las expectativas puestas en las TI, hay que buscar la explicación en que no se ha propiciado manejo inteligente y estratégico de la información, limitándose a crear islas automatizadas, sin producir los cambios necesarios en la organización para desplegar y aprovechar todas las potencialidades de las TI.

7. Tomado de CORNELLA, A.: Los recursos de información. Ventaja competitiva de las empresas. Madrid: Mc Graw-Hill, 1994, p. 69-70.

8. BRENT, D. R: En la era de la información: información, tecnología y estudio del comportamiento. En Documentación de las Ciencias de la Información, no 13, 1990, pp. 53-72.

9. MARTÍNEZ COMECHE, J.A.: Teoría de la información documental y de las instituciones documentales. Madrid: Ed. Síntesis, 1995, p. 31.

I0. CORNELLA, A,: o.c., p. 184.

|l. Idem, p. |5|.

12. VAN SLYPE, G.: Documentologie. Bruxelles: Presses Universitaires, 1988

13. BERTANLAFFY, L.: Teoría General de Sistemas. México: Fondo de Cultura Económica, 1986.

I4, BAIGET, T.: Análisis, diseño y gestión de sistemas de información (apuntes del curso de Documentalistas de la Junta de Andalucía).

15, CODINA LI.: Sistemes D'informació documental. Concepció, anàlisi y disseny de sistemes de gestió documental amb microordinadors. Barcelona: Ed. Pòrtic, 1993.
16. CODINA LI:; Modelo conceptual de un sistema de información documental. En Revista Española de Documentación Cientifica, (17) 4, 1994, p. 444

17. RAMOS SIMÓN, L. F:: Dirección, administración y marketing de empresas e instituciones documentales. Madrid: Ed. Síntesis, 1995, p. 41

18. GINCHAT, C. y MENOU M.: Introducción general a las Ciencias de la Información y Documentación. Madrid: Cindoc/Unesco, 1992, $2^{\circ}$ ed., p. 343.

19. J. CHAUMIER distingue cuatro tipos de centros de documentación, en función de su finalidad, territorialidad, especialización, etc: a) Centros nacionales interdisciplinarios; b) Centros internacionales; c) Centros especializados; d) Servicios de Información: unidades documentales integradas en la estructura de una organización a la que dan servicio. (Técnicas de Documentación y Archivo. Barcelona: Oikos -Tau, 1993, pp. 25-28)

20. ROS GARCÍA, J.: Documentación General. Sistemas, redes y centros. Madrid: Ed. Síntesis, 1994.

21. Para el estudio de los distintos modelos y grupos de Sistemas de Información puede consultarse: DEBONS, A y HORNE, E.: Information Science: An integrated view. Boston: G.K. Hall and Co., 1988

22, GINCHAT, C. y MENOU M.: Gestión y políticas de información a nivel nacional e internacional. En o.c. pp. 483-496

23. ROS GARCÍA, J. y LÓPEZ YEPES, J.: Políticas de Información y documentación. 1994.

24. LÓPEZ YEPES, J.: El desarrollo de sistemas de Información y documentación. En cuadernos E.U.B.D. Complutense, (I), 2, 1991, pp 23-33.

25. Para conocer el marco normativo autonómico que regula el sector remitimos a AGUILAR CORREDERA, F,: PAVÓN RERON, y VALVERDE CUEVAS, F: Régimen jurídico del Patrimonio Histórico en Andalucía. Sevilla: Consejería de Cultura, 1995.

26. Ley 8/83, de 3 de noviembre, de Bibliotecas. BOJA 89, 08.I I.83. Decreto 74/94, de 29 de marzo, por el que se aprueba el Reglamento del Sistema Bibliotecario de Andalucía. BOJA 70, 18.05.94

27. Decreto 249/87, de 9 de diciembre por el que se desarrolla del Biblioteca de Andalucía. BOJA4, 19,01.81

28. Ley 3//894, de 9 de enero, de Archivos. BOE 25, 30.01.84. Decreto 73/1994, de 29 de marzo, por el que se aprueba el Reglamento de Organización del sistema andaluz de Archivos y desarrollo de la Ley 3/1984, de 9 de enero, de archivos. BOJA 70, 29.03.94. 
29. Decreto 233/1989, de 7 de noviembre, por el que se establece el funcionamiento de los archivos centrales de las Consejerías, organismos Autónomos y Empresas de la Junta de Andalucía. BOJA 94, 24.1 1.89.

30. Decreto 106/1995, de 25 de abril, por el que se acuerda la formulación del Plan General de Bienes Culturales de Andalucía para el período 1996-1999. BOJA 76, 26.05 .95

31. Orden de la Consejería de Cultura y Medio Ambiente, de 14 de septiembre de 1993, por la que se aprueba el Plan de Archivos. BOJA. I I I, |4, 10.93

32. Se encuentra en elaboración un Directorio que intenta referenciar los centros de documentación que existen en las consejerías, organismos y empresas públicas de la Junta de Andalucía.

33. Una descripción ejemplificada de ambos tipos de centros puede verse en BALLESTEROS, F. y CAMACHO, E.: Gestión, tratamiento y difusión de la documentación en las Administraciones públicas. En Jornadas de Documentación Automatizada (IV. Gijón. 1994). Oviedo: Universidad, 1994, pp. 295-303.

34. Ley 6/1983, de 21 de julio, Gobierno y Administración de la Comunidad Autónoma. BOJA, 60, 29.07.83, art. 42.

35. Ley de Régimen Jurídico de la Administración del Estado. BOE, 195, 31. 07.57, arts. 16 y 19.

36. Decreto 261/88, de 2 de agosto, sobre coordinación y desarrollo de la política informática de la Junta de Andalucía. En BOJA, $73,17.09 .88$

37. La ley 8/1983, de 3 de noviembre, de Bibliotecas (BOJA, 89, 08.1 1.83) dice de esta Consejería que "planificará, coordinará e inspeccionará la organización y servicios de las bibliotecas que se integran en el Sistema de Bibliotecas de Andalucía" (art. I.4). De la lectura de esta misma ley y de su desarrollo normativo posterior se concluye que este Sistema lo constituyen las Bibliotecas Públicas, quedan excluídos los centros objeto de nuestra investigación. Existe una notoria ausencia de regulación normativa de estos centros.
38. Decreto 237/1994, de 4 de octubre, de estructura orgánica. BOJA, 08.10.94

39. Decreto 153//994, de 10 de agosto, de estructura orgánica. BOJA, 13.08 .94

40. Decreto 253/1987, de 28 de octubre. BOJA, 03.11.87

41. Decreto 6///995, de 14 de marzo. BOJA, 18.03.95

42. Decreto 253/1987, de 28 de octubre. BOJA, 03.1 I.87

43. BRAVO, J.: Del Estado centralizado al Estado autonómico: el planteamiento en materia de información y documentación. En Primeras Jornadas Españolas de Documentación Automatizada, Madrid: CSIC-CIRIT, I984, pp. 812-828

44. Confrontación España-OCDE sobre política de la información científica y técnica: Situación actual y perspectivas de la información científica y técnica en España. Madrid: Dirección General de Archivos y Bibliotecas, 1973.

45. LÓPEZ YEPES, J.: Metodología para la organización de un centro de documentación institucional en la comunidad valenciana. 1985.

46. En este campo se debe reseñar una experiencia singular, con efectos muy dinamizadores en el sector. Se trata del programa de formación mantenido por el IAAP a lo largo de más de diez años por medio del Curso de Documentalistas y reconvertido desde el curso pasado, con la colaboración de la Consejería de Cultura en el Master en Información y Documentación de la Universidad de Sevilla (MIDUS).

47. Sobre ventajas e inconvenientes de un sistema centralizado o descentralizado véase: AMAT, N.: Documentación científica y nuevas tecnologías de la información. Madrid: Pirámide, 1897, pp. 95-96 y CORNELLA, A.: o.c., pp. 122- 124.

48. BRAVO, J.: Definición y planificación de servicios técnicos de documentación en el ámbito estatal y en el ámbito autonómico. En Boletín de la Anabad, XXXV, 2-3, 1985, p. 405. 